\title{
Depression, Suicidal Ideation and the Big Five Personality Traits
}

\section{David Lester* \\ Stockton University, School of Social and Behavioral \\ Sciences, USA \\ *Corresponding author: David Lester, Stockton University, School of Social and Behavioral Sciences, Galloway, NewJ ersey, USA}

Received: January 22, 2021; Accepted: February 24, 2021; Published: March 03, 2021

\begin{abstract}
Aim: This study explored the association of the Big Five personality traits (OCEAN: openness, conscientiousness, extraversion, agreeableness and neuroticism) with current depression and a history of suicidal ideation and suicide attempts.
\end{abstract}

Methods: A sample of 115 undergraduate students in the United States was administered measures of the Beck Depression Inventory, and the 15-item Big Five personality Inventory. The students were also asked whether they had ever thought about suicide in the past and whether they had ever-attempted suicide in the past.

Results: Four of the Big Five personality trait scores (conscientiousness, extraversion, agreeableness and neuroticism) were associated with depression scores, accounting for $36 \%$ of the variance in depression scores. Among the Big Five personality traits, neuroticism was positively associated with depression, while conscientiousness, extraversion, and agreeableness were negatively associated with depression.

Conclusions: The Big Five personality traits scores did not predict a history of suicide attempts in the sample of American students, but neuroticism scores were associated with a history of suicidal ideation. USA

Keywords: Depression; Suicidal ideation; Big five; Personality; Students;

In a sample of American undergraduates, Kerby [30] found that suicidal ideation was associated with high neuroticism scores and low extraversion and agreeableness scores. In a sample of Indian undergraduates, Singh and Pathak [42] found that current suicidal ideation was associated with high neuroticism scores and with low scores for extraversion, agreeableness, openness and conscientiousness. Lester [43,44] reviewed prior research and found that low extraversion scores were consistently associated with suicidal behavior, as were high neuroticism scores. Miri and Shirazi [45] indicated that neuroticism, extraversion and agreeableness personality traits are a risk factor for suicide among Iranian people who have attempted suicide. The present study explored the association of the Big Five personality traits with current depression and a history of suicidal ideation and suicide attempts.

\section{Methods}

\section{Participants}

The participants were 115 undergraduate students enrolled in psychology courses; 85 women, 28 men and 2 who did not indicate their sex; their mean age was 21.7 years $(\mathrm{SD}=4.6)$. Participants were administered a questionnaire anonymously containing three parts.

\section{Measures}

The Beck Depression Inventory (BDI), developed by Beck et al., [46], contains 21 items (e.g., 'I feel sad much of the time') and can be used to assess the severity of depression symptoms. Each item is scored on a scale of 0 to 3 , giving a total score ranging from 0 to $[6,29,32-41]$

Austin J Psychiatry Behav Sci - Volume 7 Issue 1 - 2021 ISSN : 2381-9006 | www.austinpublishing group.com Lester. (c) All rights are reserved
Citation: Lester D. Depression, Suicidal Ideation and the Big Five Personality Traits. Austin J Psychiatry Behav Sci. 2021; 7(1): 1077. 
63: minimal depression (0-13), mild depression (14-19), moderate depression (20-28), and severe depression (29-63) [47]. The BDI has been used widely and found to have good reliability and validity [4851].

The 15-item Big Five personality Inventory (BFI-15). The Big Five personality traits (OCEAN: openness, conscientiousness, extraversion, agreeableness and neuroticism) were measured with a 15 -item scale with three items for each subscale. A typical item for openness was "I am intrigued by the patterns I find in art and nature", for conscientiousness "I never seem to be able to get organized", for extraversion "I like to be where the action is", for agreeableness "I try to be courteous to everyone I meet", and for neuroticism is "I often feel tense and jittery". The answer format was a 5-point scale with anchors 1 (strongly disagree), 2 (disagree), 3 (neither agree nor disagree), 4 (agree), and 5 (strongly agree), giving a total score ranging from 3-15 for each subscale. The BFI-15 has been used widely and found to have good reliability and validity [52]. The students were also asked whether they had ever thought about suicide in the past and whether they had ever attempted suicide in the past.

\section{Compliance with ethical standards}

The study was approved by the Institutional Review Board at Stockton University. The questionnaire contained a cover letter, explaining all the ethical considerations (confidentiality, anonymity, informed consent and the right to withdraw) as well as an explanation of the research procedure. The authors have no potential conflicts of interest with respect to the research, writing, and publication of this article. The authors received no financial support for the research, writing, and publication of this article.

\section{Data analyzes}

Data were analyzed with descriptive statistics, Pearson correlation coefficients, multiple regression, and a Principal Components Analysis (PCA) using SPSS Statistics software.

\section{Results}

Mean scores and standard deviations, the range of possible scores, and Cronbach alpha reliabilities for the present sample are shown in (Table 1). Forty-one (36\%) participants indicated that they had thought about suicide in the past, and $9(8 \%)$ said that they had attempted suicide in the past. Pearson correlations Big Five personality traits scores and depression scores are shown in (Table 1). Four of the Big Five personality traits (conscientiousness, extraversion, agreeableness and neuroticism) were associated with depression scores.

Table 1: Descriptive statistics for the scales and correlations between scale scores.

\begin{tabular}{|c|c|c|c|c|c|}
\hline & \multirow{2}{*}{$\begin{array}{c}\text { Mean } \\
\text { (SD) }\end{array}$} & \multirow{2}{*}{$\begin{array}{c}\text { Cronbach } \\
\text { alpha }\end{array}$} & \multicolumn{3}{|c|}{ Pearson correlations } \\
\cline { 5 - 7 } & Depression & $\begin{array}{c}\text { Suicidal } \\
\text { ideation }\end{array}$ & $\begin{array}{c}\text { Suicide } \\
\text { attempts }\end{array}$ \\
\hline Openness & $10.6(2.3)$ & 0.71 & -0.04 & +0.12 & +0.08 \\
\hline Conscientiousness & $11.4(2.1)$ & 0.64 & $-0.24^{* *}$ & -0.17 & +0.01 \\
\hline Extraversion & $10.4(2.1)$ & 0.62 & $-0.29^{* *}$ & -0.13 & +0.05 \\
\hline Agreeableness & $13.0(1.7)$ & 0.6 & $-0.23^{*}$ & $-0.20^{*}$ & -0.08 \\
\hline Neuroticism & $9.2(2.5)$ & 0.61 & $+0.52^{* *+}$ & $+0.22^{*}$ & +0.15 \\
\hline Depression & $8.2(7.0)$ & 0.87 & - & $+0.37^{*+*}$ & $+0.25^{* *}$ \\
\hline
\end{tabular}

Table 2: Multiple regressions to predict depression and suicidality (beta coefficients shown).

\begin{tabular}{|c|c|c|c|}
\hline & Depression & $\begin{array}{c}\text { Suicide } \\
\text { ideation }\end{array}$ & $\begin{array}{c}\text { Suicide } \\
\text { attempts }\end{array}$ \\
\hline O & 0.03 & +0.15 & +0.07 \\
\hline C & $-0.17^{\#}$ & -0.14 & +0.01 \\
\hline E & $-0.20^{* \#}$ & -0.06 & +0.09 \\
\hline A & -0.03 & -0.14 & -0.08 \\
\hline N & $+0.48^{* \#}$ & +0.16 & +0.14 \\
\hline $\mathrm{R}^{2}$ & 0.36 & 0.12 & 0.04 \\
\hline
\end{tabular}

"significant in a backward multiple regression.

Table 3: Principal components analysis for the Big Five personality Inventory (BFI-15) and Beck Depression Inventory (BDI).

\begin{tabular}{|c|c|c|}
\hline & Factor 1 & Factor 2 \\
\hline O & +0.28 & $+0.74^{\#}$ \\
\hline C & -0.28 & $+0.40^{\#}$ \\
\hline E & -0.30 & $+0.66^{\#}$ \\
\hline A & -0.51 & $+0.42^{\#}$ \\
\hline N & 0.81 & +0.03 \\
\hline Depression & $+0.81^{\#}$ & -0.16 \\
\hline Eigenvalue & 2.04 & 1.10 \\
\hline \%variance & $34.07 \%$ & $18.34 \%$ \\
\hline
\end{tabular}

In multiple regressions to predict depression scores, the $\mathrm{R}^{2}$ for the Big Five personality traits was 0.36 . However, only neuroticism scores were associated with a history of suicidal ideation, and none of the Big Five personality trait scores were associated with a history of attempted suicide (Table 2). A Principal Components Analysis (PCA) showed that all the variables loaded on two factors (Factor 1 explained 34.07\%, and Factor 2 18.34\% of total variance) (Table 3).

\section{Discussion}

The results of the present study indicated that neuroticism was positively correlated and three of Big Five personality traits (conscientiousness, extraversion, and agreeableness) were negatively associated with current depression scores. These four traits accounted for $36 \%$ of the variance in depression scores. Emotional instability plays a very important role in the development and stability of a negative mood. Because neuroticism is associated with maladaptive behavior, it causes unhealthy patterns of in person's relationship with the physical and social environment, which can lead to depression. Consistent with the findings of the present study, Leow et al., [2] reported that conscientiousness and extraversion were negatively correlated with depressive symptoms, and neuroticism positively correlated with depressive symptoms among American college students. Hosseini et al., [25] found that neuroticism had a significant positive impact on depression and was the strongest predictor trait for depression. In addition, extraversion and agreeableness had a significant negative impact on depression. Self-esteem and selfefficacy had a mediating role in the relationship between the Big Five personality traits with depression among Iranian university students. Abbasi et al., [53] showed that neuroticism had a significant positive, and extraversion a significant negative correlated with depression. These two personality traits predict depression among Iranian elderly people. Both depression and neuroticism would make theoretical 
sense. Perhaps positive emotions antagonize the negative feelings of depression, or sociality protects from depression because depression is a response to loneliness. Also perhaps conscientiousness is the pursuit of goals that suppresses depression, or maybe better relations with people resulting from greater self-discipline, or perhaps because high conscientiousness includes the suppression of emotions that could interfere with goal pursuit. Some of the suppressed emotions will be unpleasant ones, including depression. However, unlike previous research, which showed an association of Big Five personality traits with current suicidal ideation and behavior, Big Five personality traits scores were not associated with a lifetime history of suicidal ideation and attempts. In contrast, Bayrami, Eghbali, and Gholizadeh [54] reported that neuroticism was significantly and positively correlated with depression and suicidal ideation, while extraversion and conscientiousness were significantly and negatively correlated with depression and suicidal ideation. Neuroticism explained $73 \%$ of the variance of depression, and $59 \%$ of the variance of suicide. Chow et al., [55] found that personality trait of stability is a protective factor against depression and suicidal ideation in German medical students. Beautrais, Joyce, and Mulder [56] reported that low extraversion scores were associated with a history of suicide attempts, while low positive emotions were associated with a serious suicidal ideation among young people [56-62].

These present findings are limited by the cross-sectional design of the study, the use of college students with a limited age range, and the primarily female composition of the sample. The role of other variables such as self-esteem, self-efficacy, hopelessness, and coping strategies, which were not assessed in the study, may be important in the association of the Big Five personality traits and suicidal ideation and behaviour. Future research should also study current, past year and lifetime for their associations with personality traits. The associations with current suicidal ideation and behaviour may be useful for clinicians endeavouring to help suicidal clients.

\section{Conclusion}

Among the Big Five personality traits, neuroticism was positively associated with depression, while conscientiousness, extraversion, and agreeableness were negatively associated with depression. On the whole, the Big Five personality traits scores did not predict a history of suicidal ideation or suicide attempts in the sample of American students, although neuroticism scores were associated with a history of suicidal ideation.

\section{References}

1. Mccrae R, Costa P. Discriminant validity of neo-pirfacet scales. Educational and Psychological Measurement. 1992; 52: 229-236.

2. Leow K, Lee M, Lynch MF. Big five personality and depressive symptoms: A self-determination theory perspective on students' positive relationships with others. Ideas and Research You Can Use: VISTAS. 2016; 1-10.

3. Montag C, Elhai JD. A new agenda for personality psychology in the digital age? Personality and Individual Differences. 2019; 147: 128-134.

4. Montag C, Davis KL, Lazarevic LB, Knezevic G. A Serbian version of the ANPS and its link to the five-factor model of personality. Open Psychoogy. 2019; 1: 303-316.

5. Montag C, Sindermann C, Lester D, Davis KL. Linking individual differences in satisfaction with each of Maslow's needs to the Big Five personality traits and Panksepp's primary emotional systems. Helyion. 2020; 6: e04325.

6. Abdel-Khalek AM. Personality and mental health: Arabic Scale of Mental
Health, Eysenck Personality Questionnaire, and NEO Five Factor Inventory. Psychological Reports. 2012; 111: 75-82.

7. Abdel-Khalek AM. The Arabic Big Five Personality Inventory (ABFPI): Setting the stage. Psychology and Behavioral Science: International Journal. 2018; 9 .

8. Abdel-Khalek AM. Optimism, pessimism and the Big-Five personality model among Egyptian college students. Mankind Quarterly. 2019a; 60: 214-230.

9. Abdel-Khalek AM. Psychometric properties of the Arabic Big Five Personality Inventory (ABFPI). Psychology and Behavioral Science: International Journal. 2019b; 11.

10. Atari M, Maghoubirad M. The Big Five personality dimensions and mental health: The mediating role of alexithymia. Asian Journal of Psychiatry. 2016; 24: 59-64.

11. Batool N, Hanif R. Differential relationship of Big Five personality traits with positive mental health and psychopathology: Examining dual continua model of positive mental health in Pakistan. Pakistan Journal of Social and Clinical Psychology. 2018; 16: 3-9.

12. Bucher MA, Suzuki T, Samuel DB. A meta analytic review of personality traits and their association with mental health treatment outcomes. Clinical Psychology Review. 2019; 70: 51-63.

13. Dastjerdi R, Farzad V, Kadivar P. The role of five big personality factors in predicting psychological well-being. Journal of Birjand University of Medical Sciences. 2011; 18: 126-133.

14. Furnham $A$, Cheng $\mathrm{H}$. The change and stability of NEO scores over six-years: A British study and a short review. Personality and Individual Differences. 2019a; 144: 105-110.

15. Furnham A, Cheng $\mathrm{H}$. The Big-Five personality factors, mental health, and social demographic indicators as independent predictors of gratification delay. Personality and Individual Differences. 2019b; 150: 1-5.

16. Gu S-q, Xi X-I, Cheng Z-h, Wu Z-g, Wang G-q. Relationship between big five personality and mental health in college students. Chinese Journal of Clinical Psychology. 2014; 22: 354-356.

17. Hengartner MP, Kawohl W, Haker H, Rossler W, Ajdacic-Gross V. Big Five personality traits may inform public health policy and preventive medicine: Evidence from a cross-sectional and a prospective longitudinal epidemiologic study in a Swiss community. Journal of Psychosomatic Research. 2016; 84: 44-51.

18. Kotov R, Gamaz W, Schmidt F, Watson D. Linking "big" personality traits to anxiety, depressive, and substance use disorders: A meta-analysis. Psychological Bulletin. 2010; 136: 768-821.

19. Lamers SMA, Westerhof GJ, Kovacs V, Bohlmeijer ET. Differential relationships in the association of the Big Five personality traits with positive mental health and psychopathology. Journal of Research in Personality. 2012; 46: 517-524.

20. McCann SJH. Emotional health and the Big Five personality factors at the American State level. Journal of Happiness studies. 2011; 12: 547-560.

21. Molouff JM, Thorsteinsson EB, Schutte NS. The relationship between the Five-Factor Model of personality and symptoms of clinical disorders: A metaanalysis. Journal of Psychopathology and Behavioral Assessment. 2005; 27 : 101-114.

22. Salimi, M. Association between happiness and essential five factors in personality. Quarterly Journal of Social Work. 2014; 3: 41-49.

23. Chioqueta AP, Stiles TC. Personality traits and the development of depression, hopelessness, and suicide ideation. Personality and Individual Differences. 2004; 38: 1283-1291.

24. Goodwin RD, Gotlib IH. Gender differences in depression: The role of personality factors. Psychiatry Research. 2004; 126: 135-142.

25. Hosseini F, Najafi M, Mohamadi far MA. The relationship between the Big Five personality traits with depression: The mediating role of self-esteem and self-efficacy. Journal of Counselling Research. 2020; 18: 114-137. 
26. Koorevaar AML, Camijs HC, Dhondt ADF, van Marwijk HWJ, van der Mast RC, Noarding $P$, et al. Big Five personality and depression diagnosis, severity, and age of onset in older adults. Journal of Affective Disorders. 2013; 15: 178-185

27. Shi M, Liu L, Yang YL, Wang L. The mediating role of self-esteem in the relationship between big five personality traits and depressive symptoms among Chinese undergraduate medical students. Personality and Individual Differences. 2015; 83: 55-59.

28. Wang Y, Yao L, Liu L, Yang X, Wu H, Wang J, et al. The mediating role of self-efficacy in the relationship between Big five personality and depressive symptoms among Chinese unemployed population: A cross-sectional study. BMC psychiatry. 2014; 14.

29. Soltaninejad A, Fathi-Ashtiani A, Ahmadi K, Mirsharafoddini HS, Nikmorad A, Pilevarzadeh M. Personality factors underlying suicidal behavior among military youth. Iranian Red Crescent Medical Journal. 2014; 16: e12686.

30. Kerby DS. CART analysis with unit-weighted regression to predict suicidal ideation from Big Five traits. Personality and Individual Differences. 2003; 3: $249-261$.

31. Velting DM. Suicidal ideation and the five-factor model of personality. Personality and Individual Differences. 1999; 27: 943-952.

32. BlumI V, Kapusta ND, Doering S, Brahler E, Wagner B, Kersting A. Personality factors and suicide risk in a representative sample of the German general population. PloS One. 2013; 8: e76646.

33. Brezo J, Paris J, Turecki G. Personality traits as correlates of suicida ideation, suicide attempts, and suicide completions: A systematic review. Acta Psychiatrica Scandinavica. 2006; 113: 180-206.

34. Duberstein PR, Conwell Y, Seidlitz L, Denning D, Cox C, Caine E. Personality traits and suicidal behavior and ideation in depressed inpatients 50 years of age and older. The Journals of Gerontology Series B Psychological Sciences and Social Sciences. 2000; 55: 18-26.

35. Grucza RA, Przybeck TR, Cloninger CR. Personality as a mediator of demographic risk factors for suicide attempts in a community sample. Comprehensive Psychiatry. 2005; 46: 214-222

36. Hirvikoski T, Jokinen J. Personality traits in attempted and completed suicide. European Psychiatry. 2012; 27: 536-541.

37. Abdel-Khalek AM, Lester D, Dadfar M. Big Five personality factors as predictors of positive mental health. Mankind Quarterly. 1998.

38. McCann SJ. Suicide, big five personality factors, and depression at the American state level. Archives of Suicide Research. 2010; 14: 368-374.

39. Miskey HM, Hill RW, Huelsman TJ. Big five traits and perfectionism are risk factors for nonsuicidal cutting. Psychology and Behavioral Sciences. 2012 1: $1-7$

40. Segal DL, Marty MA, Meyer WJ, Coolidge FL. Personality, suicidal ideation, and reasons for living among older adults. Journal of Gerontology. Series B, Psychological Sciences and Social Sciences. 2012; 67: 159-166.

41. Singh R, Joshi HL. Suicidal ideation in relation to depression, life stress and personality among college students. Journal of the Indian Academy of Applied Psychology. 2008; 34: 259-265.

42. Singh RN, Pathak N. Big five factors and suicidal ideation among adolescents Indian Journal of Community Psychology. 2017; 13: 13-23.

43. Lester D. Extraversion and suicidal behavior. Advances in Psychology Research. 2010a; 69: 239-247.

44. Lester D. Neuroticism and psychoticism as correlates of suicidal behavior. In RG. Jackson (Ed.) Psychology of Neuroticism and Shame, pp. 235-238. Hauppauge, NY: Nova Science. 2010b.
45. Miri M, Shirazi, M. Comparison of personality traits and attitude to suicide in two groups of individuals with suicide attempts by self-immolation and drug use. Journal of Clinical Psychology. 2017; 9: 11-19.

46. Beck AT, Ward $\mathrm{CH}$, Mendelson $\mathrm{M}$, Mock J, Erbaugh J. An inventory for measuring depression. Archives of General Psychiatry. 1961; 4: 561-571.

47. Beck AT, Steer RA, Brown GK. Beck Depression Inventory Manual. Second Edition. San Antonio: Psychological Corporation. 1996.

48. Campos RC, Besser A. Depressive traits and suicide risk in young adults: A brief report. Journal of Depression and Anxiety. 2014; S2: 006.

49. Campos RC, Gonçalves B. The Portuguese version of the Beck Depression Inventory-II (BDI-II): Preliminary psychometric data with two nonclinical samples. European Journal of Psychological Assessment. 2011; 27: 258264

50. Gomez-Leal R, Megias-Robles A, Gutierrez-Cobo MJ, Cabello R, FernandezAbascal EG, Fernandez-Berrocal P. Relationship between the Dark Triad and depressive symptoms. PeerJ. 2019; 7: e8120.

51. Reinecke MA, Franklin-Scott RL. Assessment of suicide: Beck's scales for assessing mood and suicidality. Editors. In: Yufit RI, Lester D. Assessment, treatment, and prevention of suicidal behavior. 2005; 29-61.

52. McManus IC, Furnham A. Aesthetic activities and aesthetic attitudes: Influences of education, background and personality on interest and involvement in the arts. British Journal of Psychology. 2006; 97: 555-587.

53. Abbasi M, Mirderikvand F, Adavi H, Hojati M. The relationship between personality traits (neuroticism and extraversion) and self-efficacy with aging depression. Iranian Journal of Ageing. 2018; 12: 458-466.

54. Bayrami M, Eghbali A, Gholizadeh H. Interaction between personality factors and depression symptoms, hopelessness and suicidal ideation among students. Medical Journal of Tabriz University of Medical Sciences. 2012 34: 28-34.

55. Chow WS, Schmidtke J, Loerbroks A, Muth T, Angere P. The relationship between personality traits with depressive symptoms and suicidal ideation among medical students: A cross-sectional study at one medical school in Germany. International journal of Environmental Research and Public Health. 2018; 15: 1462

56. Beautrais AE, Joyce PR, Mulder RT. Personality traits and cognitive styles as risk factors for serious suicide attempts among young people. Suicide and Life-Threatening Behavior. 1999; 29: 37-47.

57. Abdel-Khalek AM, Lester D. Can personality predict suicidality? A study in two cultures. International Journal of Social Psychiatry. 2002; 48: 231-239.

58. Furnham A, McManus IC. Student attitudes to university education. Higher Education Review. 2004; 36: 29-38.

59. Furnham A, McManus IC, Scott D. Personality, empathy and attitudes to animal welfare. Anthrozoos. 2003; 16: 135-146

60. Lester D, Abdel-Khalek AM. Suicidality and personality in American and Kuwaiti students. International Journal of Social Psychiatry. 1998; 44: 280 283.

61. McManus IC, Keeling A, Paice E. Stress, burnout and doctors' attitudes to work are determined by personality and learning style: A twelve year longitudinal study of UK medical graduates. BMC Medicine. 2004; 2: 29.

62. McManus IC, Smithers E, Partridge P, Keeling A, Fleming PR. A levels and intelligence as predictors of medical careers in UK doctors: 20 year prospective study. British Medical Journal. 2003; 327: 139-142. 